\title{
versants
}

\section{Preliminar. El vuelo de Ícaro. (Poetas en el siglo XXI)}

José AndúJar Almansa

\begin{abstract}
El cuadro Paisaje con la caída de Ícaro de Pieter Brueghel es el punto de partida de este ensayo que sirve de soporte a toda una serie de reflexiones sobre la teoría y la práctica poéticas españolas en el siglo xxi.
\end{abstract}

Keywords: Paisaje con caída de Ícaro, poesía española, siglo XXI, Brueghel

La cuestión es de dónde partir. Tal vez sirva una imagen. Pienso, por ejemplo, en la escena del Paisaje con la caída de Ícaro, pintado por Brueghel. No resta demasiado espacio a la palabra, pues ya ha sido puesta a prueba por esta. Hay un poema de Robert Walser, otro de William Carlos Williams y otro de W. H. Auden que se detienen en el episodio del lienzo. El chapoteo, el grito (que no vemos, pero oímos) y el hundimiento de Ícaro en una apacible bahía del siglo xvi son ignorados por la maquinaria imperturbable de los hechos y una indiferencia generalizada (esas figuras del campesino, el pastor, un tipo pescando o los tripulantes de un bajel en primer término). Apoyados en la sabiduría vital de los maestros antiguos, Williams y Auden se proponen meditar sobre la incongruente naturaleza del sufrimiento humano en medio de un mundo que hace oídos sordos ante su testimonio, banalizándolo.

Esa extraña jerarquía con que Brueghel ha dispuesto los protagonistas de su composición nos brinda argumentos, una correspondencia. Quizás lo mueve la audacia de relegar a un segundo término el asunto mitológico, invertir la lente con que Ovidio detalla el prodigio y menciona solo anecdóticamente a sus espectadores. Pero no es esta la analogía buscada.

Como tampoco lo es que el desdichado hijo de Dédalo haya resultado el mito más fotogénico para el artista moderno desde el romanticismo. «Cualquier afán / por elevarnos / sobre la vulgaridad / tiene un límite en la vida»², escribe Walser, y entiende ese límite como un destino, una pauta. ¿Ambiciona lo mismo este verso de Ingeborg Bachmann?: «Todo el que cae tiene alas». El vértigo con que Ícaro acaba desplomándose tras su soberbio gesto

I Ovidio, Metamorfosis, VIII, 2I7-219, Obras completas, ed. A. Ramírez, Madrid, Espasa-Calpe, 2005, p. II37.

2 Robert Walser, «Boceto para La caída de Ícaro», Ante la pintura. Narraciones y poemas, ed. Bernhard Echte, Madrid, Siruela, 2009, p. 38.

3 Ingeborg Bachmann, «Se acabó el juego», Invocación a la Osa Mayor, eds. Cecilia Dreymüller y Concha García, Madrid, Hiperión, 200I, p. 25. 
traduce el fracaso de una ideología estética; el desengaño de las ambiciones sublimes y los desajustes con una realidad pragmática que ya no necesita el caduco artefacto de unas alas de cera para alentar ilusiones mucho más rentables.

Si resolvemos regresar de nuevo al cuadro es para restar algo de énfasis a sus interpretaciones tradicionales, y también para suponer, por un momento, que el personaje a quien miramos sumergirse, esa exótica ave, es el poeta del siglo Xxi. No le faltan cualidades ni carece de carácter. Se ha liberado de desafíos impuestos por su ilustre antepasado mítico. No es que su acción no lo comprometa o carezca de riesgo, pero sabe que su salto, pese a que experimente el vértigo de ese abismo que es la escritura, consiste en un salto con red, una red de lenguaje.

Por ello ha decidido no dramatizar. Descree de las cumbres y las profundidades, sin que esto le haga renunciar a los ascensos e inmersiones, esa tarea entre lo visible y lo invisible que lo define. (La pintura ha fijado ya para siempre que la mitad de su figura hundida permanezca en la superficie). $Y$ aunque conoce de antemano (y así lo confirman el ocio o las labores a su alrededor) que los principales recursos estilísticos de la vida común son la inercia y la repetición, procura no perder de vista el paisaje que le sirve de realidad. Se siente capaz de expresar cada pincelada de este, como si fueran las cosas quienes pidieran ser nombradas. Sin embargo, a medida que el cuadro se va alejando en perspectiva hacia el misterio de una montaña, una ciudadela o un horizonte de azul más incierto, comprende que sólo le vale la alusión para ese otro cuadro que comienza.

El poeta que, en medio de la indolencia ambiente, se desliza por las ambiguas aguas contemporáneas de una modernidad líquida, un arte líquido, unos sentimientos líquidos ${ }^{4}$, suele emitir dudas acerca de la identidad, lo real, lo comunicable; pero no puede permitirse algo parecido respecto a la poesía, que es una reformulación de todo lo anterior. Por ella acostumbra a ponerse en primera fila de las contradicciones, las representaciones inestables o las semánticas que apenas dan indicio de sí mismas: el Yo escrito es una perspectiva semántica que se muestra inestable y contradictoria. Eso, que lo aparta del exhibicionismo, lo distingue asimismo de confundirse con los otros, de componer un rostro sin fisuras. La normalidad es el primer síntoma de la disolución. Resulta fascinante esa frase de Brodsky, cuando equipara a la poesía con «la canción del átomo que desafía la reacción en cadena» ${ }^{5}$. Tal sucede con la insólita y minúscula figura sin alas retratada por Brueghel.

El desafío a la ley de la gravedad llevaba implícito para Ícaro la acepta-

4 Zygmunt Bauman, Arte ¿líquido?, Madrid, Sequitur, 2007.

5 Joseph Brodsky, Del dolor y la razón, Madrid, Siruela, 2015, p. I65. 
ción de un centro de gravedad único. Atribuir, por nuestra parte, un significado diferente a la escena pictórica de su caída tiene que ver con la manera en que la metáfora del vuelo reúne, mediante un proceso de afinamiento mental, realidades heterogéneas o que se aprecian incongruentes con el fin de crear una nueva congruencia. Lo que nos recuerda que el hecho de pensar hoy un poema requiere, además de una exigencia de precisión dentro de lo impreciso, un grado cada vez más acelerado de conciencia acerca de todas las opciones que han sido ya exploradas en el límite de la palabra. Algo no muy distinto a lo afirmado por Eliot en Four Quartets sobre «lo perdido / y encontrado y perdido tantas veces: y, ahora, en condiciones / que parecen adversas» ${ }^{6}$. Ese «ahora» de Eliot alberga múltiples presentes, pero nos interesa, estrictamente, el nuestro. Los movimientos de gravitación y atracción entre el Yo, la realidad y el lenguaje se han vuelto más impredecibles, dando paso a posibilidades creativas que parecen surgir de la ausencia de un centro en relación con la identidad, la percepción o el canon literario. Las «condiciones adversas» no solo ponen a prueba, sino que sugieren los estímulos expresivos en que consiste escribir hoy ese poema.

Ese poema ya no es el himno al sol de Ícaro. Su energía verbal semeja un tendido eléctrico a cuyo través fluyen estados de conciencia, imágenes, capturas mentales, tiempo sincopado, los recorridos (a la velocidad de la luz) de la elipsis y la analogía, el voltaje de las emociones como corriente alterna, intermitencias prosaicas, trozos del discurso a la deriva... He aquí el escenario en que se acoplan todos los sonidos y encajan todas las presencias: de lo aforístico a lo narrativo; de las digresiones biográficas a las ficciones autobiográficas; de la autorreferencia a la herida del referente, y de ahí a la cicatriz de esa herida; pero, además, con el desdibujamiento de fronteras entre géneros, unas fronteras sin necesidad de ser fijadas por la aduana de un poema poético, un ensayo poético, un relato poético...

Y junto a ello, el logro de una sintaxis que no persiga únicamente la pura melodía, el virtuosismo sinfónico: un texto es también un cuerpo al que oímos respirar, que bombea sangre, que tiene pulsaciones.

Como en toda pieza artística que sobrevive a lo moderno ¿aguarda al fondo la ironía? La respuesta es que sí y no. Si admitimos que predica algo concreto de nosotros en nuestra relación con el mundo, «la ironía es un verbo» ${ }^{7}$ y se conjuga en primera persona (lo dice Anne Carson). Pero si se mira a través de ella, como una lente reductora, obtendremos apenas la visión desmitificadora de una melancolía oxidada o la advertencia de que toda belleza resulta hermética. Entonces la ironía recuerda esa pequeña estatua de

6 T. S. Eliot, La tierra baldía, Cuatro cuartetos y otros poemas. Poesía selecta (I909-I942), eds. Juan Malpartida y Jordi Doce, Barcelona, Círculo de Lectores, 200I, p. I65.

7 Anne Carson, «La ironía no basta: ensayo sobre mi vida como Catherine Denueve (Segundo borrador)», Hombres en sus horas libres, ed. Jordi Doce, Valencia, Pre-Textos, 2007, p. 283. 
sal que llevan los escépticos en el bolsillo y representa Zbigniew Herbert en su poema «De la mitología». El riesgo de convertir esa estatuilla en una deidad consiste en que no siempre resulta infalible, también el sistema acaba integrándola como mero condimento. En el texto de Herbert eran «los bárbaros», personificación de un pasado histórico muy concreto, quienes sazonaban con dicha sal sus platos; nuestro tiempo señala al «hombre sin atributos», que profesa el nihilismo por falta de imaginación. Herbert nos anima a entender la ironía de un modo semejante a como expresa Brueghel su paisaje alegórico: no solo un agente contra la mediocridad de los estereotipos, sino un paisaje con dos líneas rojas que avanzan paralelas y en ocasiones se tocan: las preguntas que no dejamos de plantearnos y las dudas que, a su vez, nos enseñan a dudar de la duda.

No es posible ya una reivindicación de la cultura en términos, por ejemplo, como los empleados por George Steiner en El castillo de Barba Azul. Más bien todo lo contrario: nos sentimos tentados de entonar un blues por la alta cultura. Si la más poética de las profecías de Marx declaraba que «todo lo sólido se desvanece en el aire», un representante del «Spoken Word» bien puede argüir que todo lo etéreo se consolida en la red. Los blogs, los posts: la ubicua literatura de nuestro tiempo. La cuestión es si en la red, efectivamente, reside la oportunidad única de democratizar la cultura. Es decir, esa Gran Biblioteca de la era digital para cuya composición en este mismo instante miles de manos anónimas fusilan impávidos libros sobre escáneres de última tecnología. Se trata, como todo pensamiento utópico, como todo afán totalizador, de algo contra lo que debemos estar prevenidos. Al fin y al cabo, la biblioteca universal, con la que ya fantaseara Borges, acaba adoptando la traza de un laberinto ideado para extraviar el orgullo desmedido de los hombres, un lugar donde Dédalo cobra el protagonismo de Ícaro. Los peligros ideológicos inherentes a la antigua auctoritas no pueden inspirarnos menos temor que la ingenua creencia de que son los consumidores, los espectadores, los cibernautas quienes deciden en todo momento por sí solos. Admitamos al menos el riesgo de que la deseable universalización de los saberes adopta en muchos casos el rostro único de la homologación y el consumo. El espectáculo de la cultura pone en escena una sola máscara, indiscernible de la tragedia o la comedia, establece fronteras dudosas pero rentables entre la verticalidad y la horizontalidad, entre el ocio y el arte, entre el reconocimiento y el éxito.

Observaba Eugenio Montale en su discurso de recepción del Premio Nobel en 1975 que la influencia del lenguaje poético sobre el pulso de la realidad había resultado muchas veces un "latigazo decisivo» ${ }^{8}$. Montale tituló su discurso ante la Academia de Suecia «¿Es todavía posible la poesía?». Piensa

8 Eugenio Montale, De la poesía, Valencia, Pre-Textos, 1995, p. 2 I2. 
en ella como barrera y reflexión ante el «universo de las comunicaciones de masas»". Hoy sabemos que muchas de las sugestiones y destrezas retóricas de lo poético resultan una herramienta indispensable para los mensajes publicitarios.

¿Se puede hacer en nuestros días una defensa de la poesía parecida a la de Montale? En su ensayo Contra los poetas, el escritor polaco Witold Gombrowicz planteaba una denuncia contra el gremio que no dudó en trasladar a muchos de sus productos patentados. Lo hacía por las mismas razones, y con igual vehemencia, que se ataca al Estado y a todas esas formas fantasmales que dejan de representar para el hombre un cómodo abrigo y se convierten en rígido y pesado caparazón.

¿Por qué no me gusta la poesía pura? -argumentaba Gombrowicz- Por los mismos motivos por los que no me gusta el azúcar puro. El azúcar encanta cuando lo tomamos junto con el café, pero nadie se comería un plato de azúcar: sería ya demasiado ${ }^{10}$.

A Gombrowicz la poesía pura, desde Mallarmé a las vanguardias, se le antojó una suerte de extracto farmacéutico y depurado. Palabras destiladas en un alambique.

Convengamos en que resulta tedioso, e incluso algo nocivo, cuando los poetas deciden escribir solo para los poetas y abdican de su diálogo con la realidad. Como los cortadores que usan diamantes para tallar otros diamantes. Su labor se parece entonces a la de tantos mundos especializados y herméticos que disgregan con cinismo la sociedad contemporánea: el poder, la economía, la ingeniería bursátil. Mundos que vienen revistiéndose, de un modo teológico y sombrío, con los rasgos propios de una metáfora vacía.

Aunque quizás podríamos valernos de idénticos argumentos para desconfiar, de manera todavía más profunda, de la facilidad. Lo fácilmente entendible, las zonas de confort expresivo, retratan nuestro reino de lo fútil, el degradado paraíso de los eslóganes. El hedonismo de los estribillos. Lo pegadizo de la sintonía.

Vivimos una época de relativismos que ha patentado un concepto híbrido de lo estético, un modo igualmente idóneo de fracturar como de facturar la realidad en múltiples escenarios consumibles. Desde perturbadoras y envolventes metáforas publicitarias y colosales proyectos urbanísticos, hasta los triviales comentarios con que las páginas de Lonely Planet pretenden ilustrar el viaje de Ícaro. En su libro La estetización del mundo, Lipovetsky y Serroy han definido este proceso que se extiende a todo el planeta, y que

9 Ibid.

Io Witold Gombrowicz, Contra los poetas, Madrid, Sequitur, 2009, p. I4. 
otros autores identifican con una idea crepuscular del arte como experiencia elevada. Confío en que el lector del presente número de Versants encontrará razones para negar esto último. Aun así, conviene admitir que el panorama que se dibuja resulta sin duda más complejo, y quizás antagónico, del que llevó a Baudelaire en el preludio de la modernidad a debatirse entre la hegeliana "prosa del mundo" y los Pequeños poemas en prosa. El panorama de un «capitalismo artístico» para el que la nostalgia o la elegía han sido reemplazadas por el culto mercantilista del vintage, o donde los grandes centros y galerías comerciales, en cuyo ensueño operístico nos extraviamos, proporcionan la experiencia de un tiempo postergado.

La posmodernidad es una posmetafísica. La poesía se ve obligada, una vez más, a pensarse, a cambiar de conversación y de rutina. Tiene la continua sensación de que le siguen los pasos, de que un día de estos acabarán por darle alcance. El tiempo de que a la inquietud le palpite un corazón es siempre el tiempo de la poesía. 